- Research in Language 2007, vol. 5

DOI: 10.2478/v10015-007-0008-0

\author{
Waldemar Skrzypczak ${ }^{*}$
}

Nicolaus Copernicus University, Toruń

\title{
TOPOLOGICAL MODELLING OF GRAMMATICAL AND LEXICAL ASPECT IN ENGLISH
}

\begin{abstract}
:
This paper stems from a broader research project entitled Analog-based Modelling of Meaning Representations in English (Skrzypczak 2006), and aims to present grammatical aspect and lexical aspect as two modes of encoding the temporal profiles within the conceptualisation of processes (terminologically, in Langackerian sense, imperfective and perfective processes, otherwise, variously labelled as stative and dynamic verbs, i. e. states vs. discrete 'unitary' events and nondiscrete 'unbounded' processes).

It is assumed that aspect in both cases - as a process-profiling category - is analogous to the profiling of things and atemporal relations (in the sense of Langacker 1987, 1990, 2000), given the maximisation of the temporal domain in the characterisation of processes (perfective and imperfective, hence: dynamic and stative), and minimalisation of the temporal domain during the conceptualisation of things (conceptually independent entities) and atemporal relations (conceptually dependent atemporal configurations). The analogy between nouns and verbs in terms of 'granularity' has been so far variously addressed by Langacker (1990), Jackendoff (1991) and Talmy (2001), and also constitutes the core assumption in my research on topological modelling.
\end{abstract}

Keywords: grammatical and lexical aspect, states, events, processes, profiling.

\section{Introductiory note}

The paper aspires to present three modes of encoding aspect:

(a) grammatical aspect (broadly understood in terms of perfective/progressive constructions involving primary auxiliaries BE and/or HAVE along with appropriate present and past participle forms

(b) lexical aspect (akin to Aktionsart), involving the profiling of a temporal situation within the 'internal semantics' of the verb alone

(c) an attempt at an integration of grammatical aspect with various types of lexical aspects.

* Author's address: Departament of English, Nicolaus Copernicus University, ul. Fosa Staromiejska 3,87-100 Toruń; e-mail: spaceout@uni.torun.pl 
In order to arrive at possibly full and clear descriptions three different conventions have been used respectively for: (a) the grammatical aspect (granularity and entity-like, substance-like and container-like ontological representations, akin to respective nominal analogs), (b) lexical aspect (illustrated within the spatio-temporal frame; vertical for 1-dimensional space, horizontal for 1-dimensional time; also 'translated' into the entity-substance-container analogs), and (c) an attempted integration of both grammatical and lexical aspects, which can be referred to as a special kind of 'blending' along the morpho-syntactic spectrum (also akin to a special kind of compositionality in Langacker's sense of profile determinants and elaboration sites).

\section{Aspectuality matrix}

It is assumed that aspect concerns the conceptual profiling of:

1. states (stative verbs)

2. events (dynamic punctual)

3. processes (dynamic durative)

4. their starting and terminal points (points of change) in space-time as well as

5. their segmentation into smaller (uniplex-multiplex) units.

It is assumed that image schematic transformation processes akin to what we have observed with uniplex, multiplex, substance conceptual entities (things, encoded as nominals) (cf. Skrzypczak 2006) along with the actual/virtual containment may be of import in the treatment of the category of aspect among processes encoded as verbs (in the special sense of Langacker's treatment: 1987, 1990, as perfective and imperfective, hence: dynamic and stative). The difficulty lies in the fact that the category of aspect regards both grammatical aspect (more transparent morpho-syntactically) and lexical aspect, implicit in the multidimensional matrix of internal parameters within a single verbal-lexical exponent resting on multiple dimensions coactivated by virtue of subcategorisation, collocability, argument structure, causation, agency etc.

\section{Aktionsart}

Traditionally known in terms of Aktionsart (cf. Jackendoff 1991; Van Valin and LaPolla 1997; Pustoyevsky 1988, 1991 after Stalmaszczyk 1999), but also variously labelled in other sources (cf. dictionaries of linguistic terms, cf. Crystal 1991, Matthews 1997): perfective vs. imperfective verbs, telic vs. atelic, inchoative (inceptive), durative, punctual, iterative, frequentive, habituals etc. 
Verb classes require specification in terms of boundedness (discreteness/non-discreteness) and dynamicity. The conception of Aktionsart (German form of action; Vendler 1957, after Van Valin and LaPolla 1997; W. Croft $1991)^{1}$ - predicting syntactic structure from semantic representation; four basic classes of verbs and other predication elements could be classified in terms of their inherent temporal properties:

1. states: non-dynamic temporally unbounded (be sick, be tall, have, love, know, believe...)

2. achievements: instantaneous changes which have an inherent terminal point (explode, collapse, shatter [intransitive]...)

3. accomplishments: temporarily extended, not instantaneous changes of states leading to a terminal point (melt, freeze, dry [intransitive] + learn)

4. activities: dynamic, temporally unbounded (march, walk, roll [intransitive] swim, read, eat...) (Van Valin and LaPolla 1997: 91)

Three features are required:

[+/- static] happening/non-happening

[+/-punctual] instantaneous vs. takes place over time span

[+/-telic] having a terminal point/not having a terminal point

\begin{tabular}{|l|l|}
\hline State of affairs & Aktionsart type \\
\hline Situation & State [+static][-telic][-punctual] \\
\hline Event & Achievement [-static][+telic][+punctual] \\
\hline Process & Accomplishment [-static][+telic][-punctual] \\
\hline Action & Activity [-static][-telic][-punctual] \\
\hline
\end{tabular}

For example (in my own graphic convention):

The balloon popped. $>\cdot<$

The balloons are popping. ... $>\cdot<\sim>\cdot<\sim>\cdot<\sim>\cdot<\ldots$

(iterative interpretation as a result of adding the progressive to the +punctual)

Consider also aspectuality changing with regard to preposition in the temporal expression:

$\mathrm{x}$ dried for 5 minutes/ $\mathrm{x}$ ate spaghetti for 10 minutes

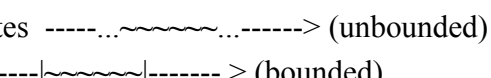

$\mathrm{x}$ dried in 5 minutes/ate spaghetti in 10 minutes

(Van Valin and LaPolla 1997: 96)

\footnotetext{
${ }^{1}$ Cf. also Stalmaszczyk (1999: 169-172).
} 
Similarly: drink, write, paint, carve will behave like activities if they have a nonspecific, indefinite, generic or mass noun object, but they behave like accomplishments if they have a specific, quantified object which serves to delineate the action:

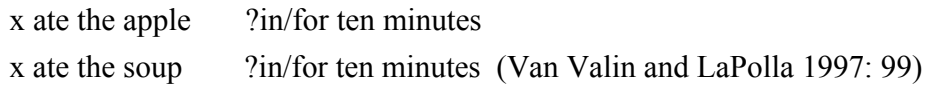

Thus, lexical representations for verbs in terms of logical structures of formal semantics can be rendered as follows:

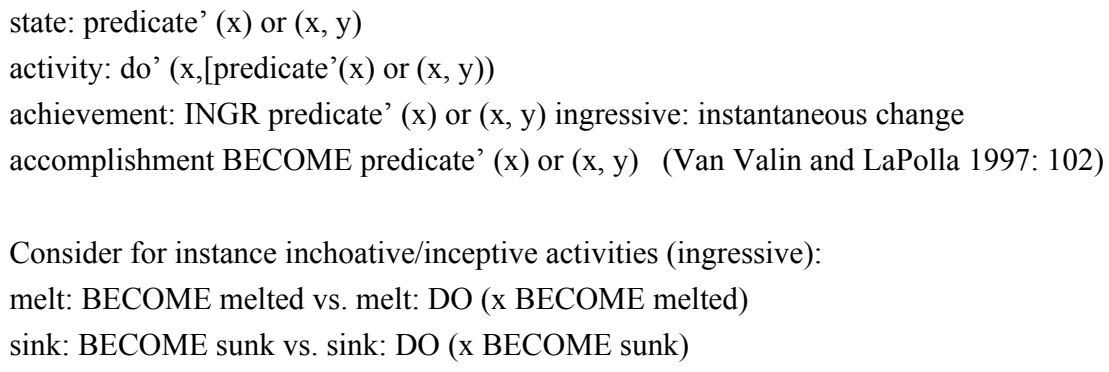

\section{Granularity}

Consider the following superschematic matrix derived from the object uniplex/multiplex, mass, container for things analog (a 'two-way temporal extension').

The representation below assumes:

(a) generic-idealised granularity (understood as a 'level of detail' akin to visual granularity in photography)

(b) time (below) is assumed to be counteractive relative to the flow of events (cf. the flow of events $\sim$ flow of time dual) (Lakoff 1993, Skrzypczak 2006), which results in the apparently symmetrical and 'stative/fossilised' character of this heuristic representation of states, events and processes:

(c)

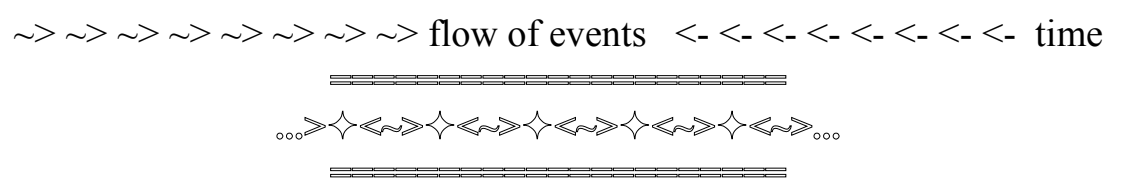


Instantiations of the above generic matrix open themselves to various profiling instances (akin to metonymic profile shifts; note also: high level granularity):

\begin{tabular}{|l|c|}
\hline uniplex events e. g. I dropped a coin. \\
\hline $\begin{array}{l}\text { discrete-entity-like repeated events } \\
\text { e. g. I was stumping my feet. }\end{array}$ \\
Moment verbs/telic: \\
hit, kick, knock, drop...
\end{tabular}

Fig. 1. Events, processes and states in the generic convention. (Note that their respective nominal counterparts would be: discrete entities, substances and containers.)

Further extraction and granular segmentation along with notational simplification into 'discrete' units is also possible, for example:

I dropped $[\uparrow][\uparrow][\uparrow][\uparrow][\uparrow]$ the coin five times. (discrete event segmentation)

I played $[\sim][\sim][\sim][\sim][\sim][\sim]$ the game five times. (extended event segmentation)

I have been/lived $[=][=][=][=][=]$ to/in Spain five times. (state segmentation)

The above can also yield possible nominalisations:

The multiple dropping of the coin bothered Jim.

Playing the game five times in a row wore me out.

Living in Spain on five separate occasions made me more sensitive to cross-cultural intricacies.

This and many other issues show that languages can encode meaning along the object-oriented parameters as well as action-oriented parameters, as in the example: 


\begin{tabular}{|c|c|}
\hline $\begin{array}{l}\text { 1. The Earth }{ }_{\mathrm{TR}} \text { is moving. } \\
\text { Subject+Verb }\end{array}$ & $\begin{array}{l}\text { 2. The } \operatorname{Earth}_{\mathrm{TR}} \text { in a state } \\
\text { (cf. a spoon in a cup of tea) } \\
{[[[\mathrm{NP}] \mathrm{PP}] \mathrm{PP}]}\end{array}$ \\
\hline 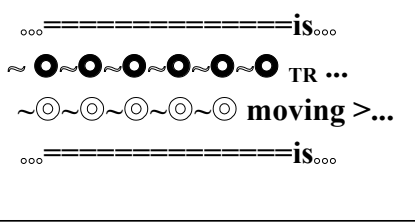 & 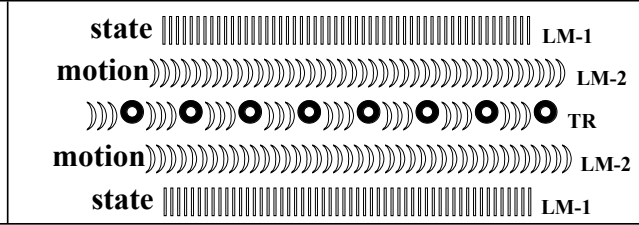 \\
\hline 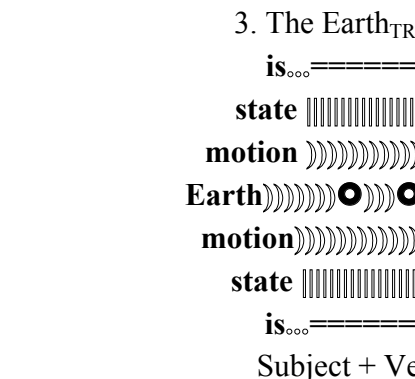 & 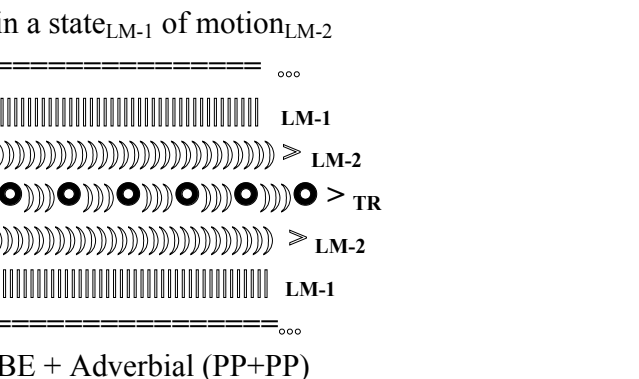 \\
\hline
\end{tabular}

Fig. 2. Integration of (1) a clause into (2) a nominal structure to be incorporated into (3) another clause.

\section{Grammatical aspect}

Before we consider the question of lexical aspect, let us assume an idealised model of aspect, along with the categories of tense and voice, in the morphogrammatical dimension. The distinction between states, discrete events and nondiscrete processes will be matched later against a set of internal parameters incorporated into the verb structure. ${ }^{2}$

One might also incorporate a fairly stable idealised model for tense shifts in reported speech and the sequence of tenses, as well as conditional constructions (cf. Skrzypczak 2001).

\footnotetext{
${ }^{2}$ The model was developed in Skrzypczak (1988, 1990, 1991, 2001).
} 


\begin{tabular}{|c|c|c|c|c|}
\hline & $\begin{array}{l}\text { Past } \\
\text { X said } \\
\text { X knew } \\
\text { X thought } \\
\text { X believed THAT } \\
\text { X asked IF/WH- } \\
\text { (matrix for reported } \\
\text { speech or tense } \\
\text { sequence) } \\
\mathbf{1}\end{array}$ & $\begin{array}{l}\text { Modal Past } \\
\text { Would } \\
\text { Should } \\
\text { Could } \\
\text { Might } \\
----- \\
\text { Ought to } \\
\\
\mathbf{- 1 + m}\end{array}$ & $\begin{array}{l}\text { Present } \\
\text { X say(s) } \\
\text { X know(s) } \\
\text { X think(s) } \\
\text { X believe(s) THAT } \\
\text { X ask (s) IF/WH- } \\
\text { (no tense shift with } \\
\text { this matrix) } \\
\text { Ground } \mathbf{0}\end{array}$ & $\begin{array}{l}\text { Modal Present } \\
\text { Will } \\
\text { Shall } \\
\text { Can } \\
\text { May } \\
\text { Must } \\
------ \\
\\
\mathbf{0 + m}\end{array}$ \\
\hline $\begin{array}{l}\text { State } \\
\text { Event } \\
\text { or habitual } \\
\text { segmented }\end{array}$ & 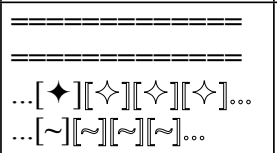 & 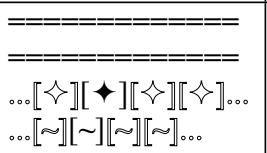 & $\begin{array}{l}=========== \\
============ \\
\ldots[\uparrow][\uparrow][\uparrow][\uparrow] \ldots \\
\ldots[\sim][\sim][\sim][\sim] \ldots\end{array}$ & 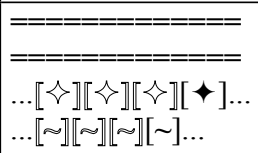 \\
\hline $\begin{array}{l}\text { Simple } \\
\text { Active }\end{array}$ & X V-ed $\rightarrow Y$ & $\mathrm{X}$ would $\mathrm{V} \rightarrow \mathrm{Y}$ & X V (-s) $\rightarrow Y$ & $\mathrm{X}$ will $\mathrm{V} \rightarrow \mathrm{Y}$ \\
\hline $\begin{array}{l}\text { Simple } \\
\text { Passive }\end{array}$ & $\begin{array}{l}\text { Y was V-en } \\
\leftarrow \text { (by } X)\end{array}$ & $\begin{array}{l}\text { Y would be V-en } \\
\leftarrow(\text { by } X)\end{array}$ & $\begin{array}{l}\text { Y am/are/is V-en } \\
\leftarrow(\text { by } X)\end{array}$ & $\begin{array}{l}\text { Y will be V-en } \\
\leftarrow \text { (by X) }\end{array}$ \\
\hline $\begin{array}{l}\text { Process } \\
\text { or a series of } \\
\text { events Non- } \\
\text { segmented }\end{array}$ & $\begin{array}{l}\sim \sim \sim \sim \sim \sim \sim \sim \\
\sim \prec \sim \prec \sim \prec \sim \prec \sim \downarrow \sim \\
\sim \uparrow \sim \uparrow \sim \uparrow \sim \uparrow \sim \uparrow \sim\end{array}$ & $\begin{array}{l}\sim \sim \sim \sim \sim \sim \sim \sim \sim \\
\sim \diamond \sim \downarrow \sim \downarrow \sim \downarrow \sim \downarrow \sim \\
\sim \uparrow \sim \uparrow \sim \uparrow \sim \uparrow \sim \uparrow \sim\end{array}$ & $\begin{array}{l}\sim \sim \sim \sim \sim \sim \sim \sim \sim \\
\sim \prec \sim \prec \sim \prec \sim \prec \sim \prec \sim \\
\sim \uparrow \sim \uparrow \sim \uparrow \sim \uparrow \sim \uparrow \sim\end{array}$ & $\begin{array}{l}\sim \sim \sim \sim \sim \sim \sim \sim \\
\sim \downarrow \sim \downarrow \sim \downarrow \sim \downarrow \sim \downarrow \sim \\
\sim \uparrow \sim \uparrow \sim \uparrow \sim \uparrow \sim \uparrow \sim\end{array}$ \\
\hline $\begin{array}{l}\text { Progressive } \\
\text { Active }\end{array}$ & $\mathrm{X}$ was $\mathrm{V}$-ing $\rightarrow \mathrm{Y}$ & $\begin{array}{l}X \text { would be } V \text {-ing } \\
\rightarrow Y\end{array}$ & $\begin{array}{l}\mathrm{X} \text { am/are/is } \mathrm{V} \text {-ing } \\
\rightarrow \mathrm{Y}\end{array}$ & $\underset{\rightarrow Y}{X \text { will be } V \text {-ing }}$ \\
\hline $\begin{array}{l}\text { Progressive } \\
\text { Passive }\end{array}$ & $\begin{array}{l}\text { Y was being V-en } \\
\leftarrow(\text { by } X)\end{array}$ & $\varnothing$ & $\begin{array}{l}\text { Y am/are/is being } \\
\text { V-en } \leftarrow \text { (by } X)\end{array}$ & $\varnothing$ \\
\hline $\begin{array}{l}\text { State } \\
\text { Event } \\
\text { Anterior }\end{array}$ & $\begin{array}{l}========= \\
========== \\
{[\uparrow]---\cdot-------} \\
{[\sim]--\cdot--\cdot-\cdot---}\end{array}$ & 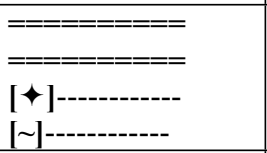 & $\begin{array}{l}========== \\
========== \\
{[\uparrow]-----\cdot-\cdot----} \\
{[\sim]------\cdot-----}\end{array}$ & 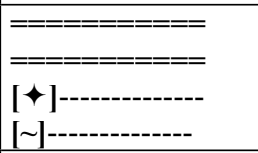 \\
\hline $\begin{array}{l}\text { Perfect } \\
\text { Active }\end{array}$ & X had V-en Y & $\begin{array}{l}X \text { would have } \mathrm{V} \text { - } \\
\text { en } \mathrm{Y}\end{array}$ & $\begin{array}{ll}\mathrm{X} & \text { have/has } \text { V-en } \\
\mathrm{Y} & \\
\end{array}$ & $\begin{array}{l}\mathrm{X} \text { will have } \mathrm{V} \text {-en } \\
\mathrm{Y}\end{array}$ \\
\hline $\begin{array}{l}\text { Perfect } \\
\text { Passive } \\
\end{array}$ & $\begin{array}{c}\text { Y had been } \\
\text { V-en (by X) } \\
\end{array}$ & $\begin{array}{l}\text { would have } \\
\text { been } \text { V-en }(\text { by } X)\end{array}$ & \begin{tabular}{|l} 
have/has been \\
V-en (by X)
\end{tabular} & $\begin{array}{l}\text { Y will have been } \\
\text { V-en (by X) }\end{array}$ \\
\hline $\begin{array}{l}\text { Process } \\
\text { or a series } \\
\text { of events } \\
\text { anterior rela- } \\
\text { tive to a point } \\
\text { of reference }\end{array}$ & $\begin{array}{l}\sim \sim \sim \sim \sim \sim \\
\sim \curlyvee \sim \downarrow \sim \downarrow \sim ~ \\
\sim \uparrow \sim \uparrow \sim \uparrow \sim ~\end{array}$ & 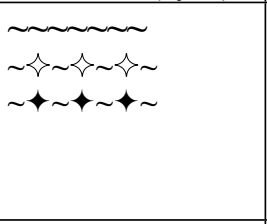 & 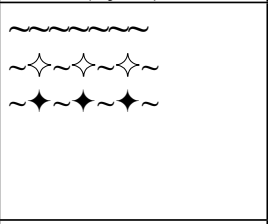 & $\begin{array}{l}\sim \sim \sim \sim \sim \sim \\
\sim \nLeftarrow \sim \downarrow \sim \downarrow \sim \\
\sim \leftrightarrow \sim \uparrow \sim \uparrow \sim ~\end{array}$ \\
\hline \begin{tabular}{|l|} 
Perfect \\
Progressive \\
Active \\
\end{tabular} & $\begin{array}{l}X \text { had been } V \text {-ing } \\
Y\end{array}$ & $\begin{array}{l}\text { X would have } \\
\text { been } \text { V-ing Y }\end{array}$ & $\begin{array}{l}X \text { have/has been } \\
\text { V-ing } Y\end{array}$ & $\begin{array}{l}X \text { will have been } \\
V \text {-ing } Y\end{array}$ \\
\hline $\begin{array}{l}\text { Perfect } \\
\text { Progressive } \\
\text { Passive }\end{array}$ & $\varnothing$ & $\varnothing$ & $\varnothing$ & $\varnothing$ \\
\hline
\end{tabular}

Fig. 4. A generic matrix representation for the grammatical aspect (no fine granularity elaborations for lexical aspectual profiles included). The semantic spaces (image-based representations) are presented above their respective morpho-syntactic coding representations. 


\section{Lexical aspect}

An idealised topological spatio-temporal model for states, events and processes (at a more detailed level of granularity) requires a co-ordinate representation of spatio-temporal continuum as 1-D space (vertically represented) and 1-D time (horizontally represented). 1-D space and 1-D time seem to be sufficient for the characterisation of one-argument stative and dynamic verbs at the generic level.

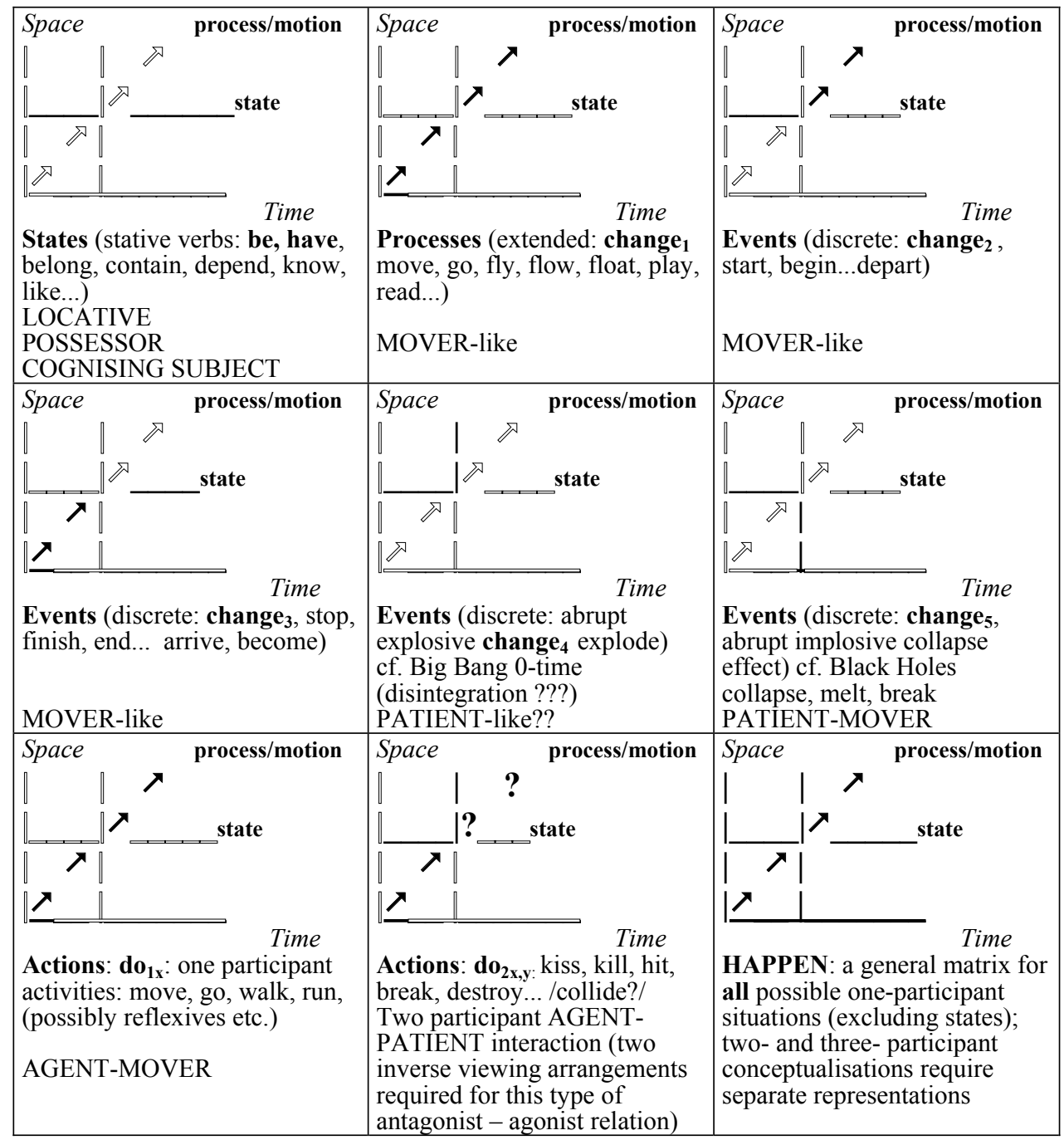

Fig. 5. Spatio-temporal coordinates for further elaboration of various dimensions of aspectual profiles at the lexical level (lexical aspect). Two and three argument verbs will further require an integration of more frames of reference). 
We might even insist on a thought experiment that both time and space are 'stative' dimensions and it is only the parametrisation along the change - no change distinction that renders the dynamicity of both (space and time). Of course, one needs to bear in mind the fact that mind is a process itself, thus we also need to distinguish between space and time as objects of conceptualisation and space and time as vehicles for conceptualisation.

Consider further the successive profiles of: depart/leave for a location, arrive at a location, and return (one argument):

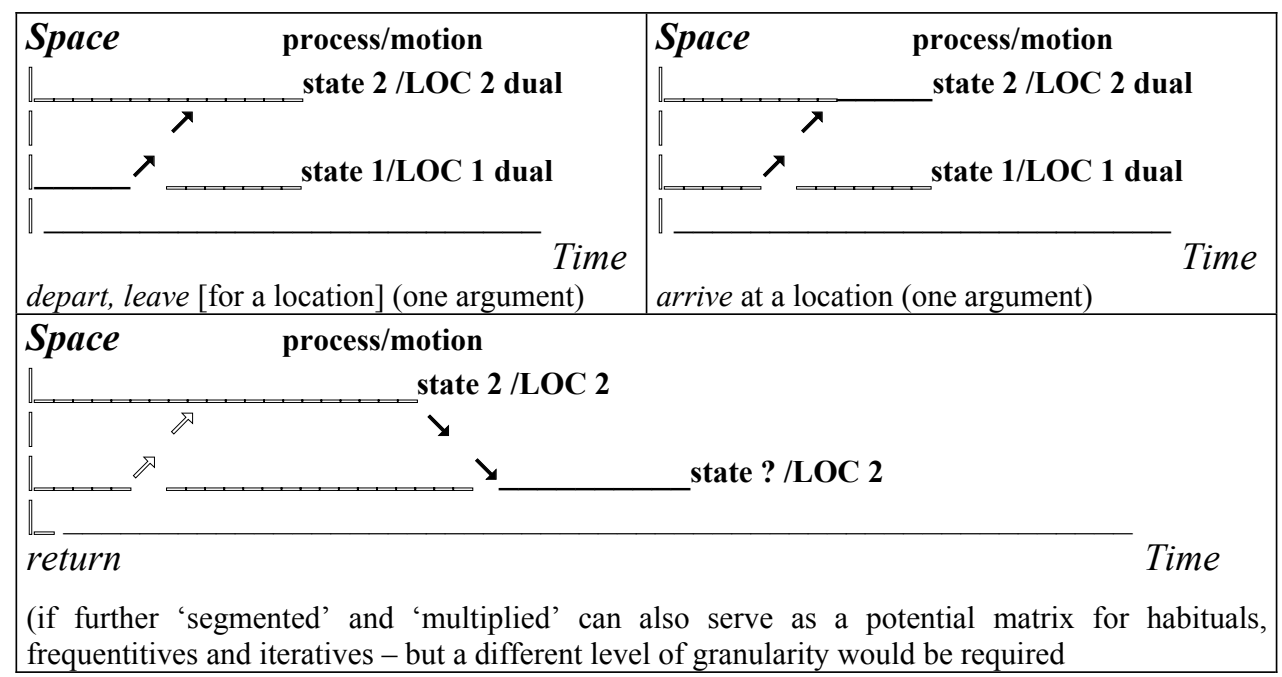

Fig. 6. Depart, arrive and return - in the spatio-temporal convention.

Note the paradoxical nature of the state location dual in depart $[\bullet \operatorname{loc} 1 \rightarrow$ ] and arrive $[\rightarrow \bullet \operatorname{loc} 2]$, and return [loc $1 / \mathrm{t} 1 \Rightarrow \operatorname{loc} 2 / \mathrm{t} 2 \rightarrow \bullet \operatorname{loc} 1 / \mathrm{t} 3]$, but states are entangled in time and events and processes. Thus, paradoxically, the state motion coincidence (dual) needs to be treated as a product of alternate conceptualisation. Similarly, as above, steady-state motion can also be considered as a state (cf. The Earth is in a state of motion). By the same token, state location coincidence (dual) renders departure from a location as a departure from a state of affairs, which can be variously explained in terms of duals (Lakoff 1993), focal adjustments and construal operations, alternate construals, virtuality (Langacker 1997, 1990, 2001), image-schematic transformations (Lakoff 1987, Johnson 1987) etc ${ }^{3}$.

\footnotetext{
${ }^{3}$ By virtue of transitivity, we can identify object location duals, objects as states (=stative existence), return of an object (=in its own stative existence) to a previous location is paradoxically
} 
Consider the metaphorical rendering of: to be in shape, to be out of shape, to return to shape/recover shape, $\mathrm{X}$ [returned] to shape:

\begin{tabular}{|c|c|c|}
\hline $\begin{array}{l}\mathrm{X} \text { is in shape: } \\
\text { object } \mathrm{X}_{\mathrm{TR}} \text { and } \\
\text { shape } \mathrm{Y}_{\mathrm{LM}} \text { (standard) } \\
\left(\mathrm{X}_{\mathrm{TR}}=\mathrm{Y}_{\mathrm{LM}}\right)\end{array}$ & $\begin{array}{l}\mathrm{X} \text { is not in shape }= \\
\mathrm{X} \text { is out of shape: } \\
\text { object } \mathrm{X}_{\mathrm{TR}} \text { and shape } \mathrm{Y}_{\mathrm{LM}}(\mathrm{TR} \neq \\
\mathrm{LM}) \\
\mathrm{X}_{\mathrm{TR}}>\mathrm{Y}_{\mathrm{LM}} \text { and } / \text { or } \mathrm{X}_{\mathrm{TR}}<\mathrm{Y}_{\mathrm{LM}}\end{array}$ & $\begin{array}{l}\mathrm{X} \text { back in shape } \\
\mathrm{X}_{\mathrm{TR}}=\mathrm{Y}_{\mathrm{LM}} \\
\text { (having returned to shape/ having } \\
\text { come back to shape) }\end{array}$ \\
\hline 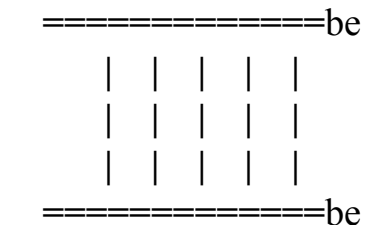 & $\begin{array}{c}==========\text { be } \\
\|) \|) \|) \|) \|) \\
(\|(\|(\|(\|(\|) \\
\|) \|) \|) \|) \|) \\
===========\text { be }\end{array}$ & 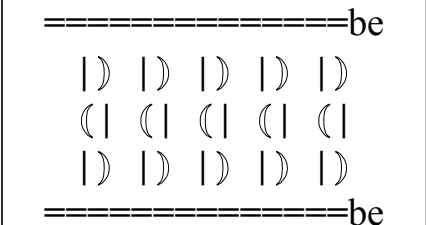 \\
\hline
\end{tabular}

Fig. 7. Return to shape translated into a simplified convention (space-time integrated)

A transformation (let us call it a 'topological translation') of the above representation into more iconic and experientially verifiable models would involve the following correlates for the schematic circular return and its instantiations:

$U$

\begin{tabular}{|c|c|c|}
\hline$\bigcap$ & $\cup$ & $\subset$ \\
\hline$\uparrow \downarrow$ & $\downarrow \uparrow$ & $\leftarrow$ \\
$\begin{array}{l}\text { throwing a stone upwards and } \\
\text { its returning (falling) }\end{array}$ & $\begin{array}{l}\text { diving down deep into } \\
\text { water and returning }\end{array}$ & $\begin{array}{l}\rightarrow \\
\text { leaving a location horizontally } \\
\text { in any direction (front-back, } \\
\text { left-right) and returning }\end{array}$ \\
\hline
\end{tabular}

Fig. 8. The topological flexibility of to return in terms of spatial orientations

The common denominator for all the above motion away from and the reverse motion towards the same location, which is lexicalised in English in terms of circularity re-turn/turn back. This gives rise to such mathematical representations as the sinusoid function for cyclicity, which is one more indication that

a return to a location, but not the same state of affairs, even though common language renders a return to a previous location as a return to the previous state. Thus, individuation of elements in time-space, such as objects, locations and events is a matter of non-summative transitions (transformations) which involve all the elements in question (inherent in the superschematic matrix) at the same time. Therefore, the state container metaphor is yet another manifestation of the paradoxical nature of existence. 
mathematics, as we know it, is inbuilt into bodily experience and emerges from it as a form of abstracted conceptualisation and not vice versa.

The space-time duality of our experience is heavily unidirectional (at least on the level of conscious experience of the actual macro-world that is peripherally accessed in real time), since we can return to locations in space, whereas we cannot return to locations in time, as well as our deeds in the external reality cannot be undone, hence also the cause-effect structure is doomed to be irreversible. In the epistemic realm however (virtual reality), in the domain of autonomous processes, memory accommodates cognising agents with the faculty of temporal displacement (memory can be explored) and counterfactual displacement (possible realities can be created).

Apart from the experientially verifiable models most of the verbs, we might also assume some highly speculative idealised models for a nuclear reaction (mutual explosion and splitting of particles, where the time value approaches zero), and a highly speculative idealised models for creation (becoming alive) and utter irreversible decay (the terminal point of dying).

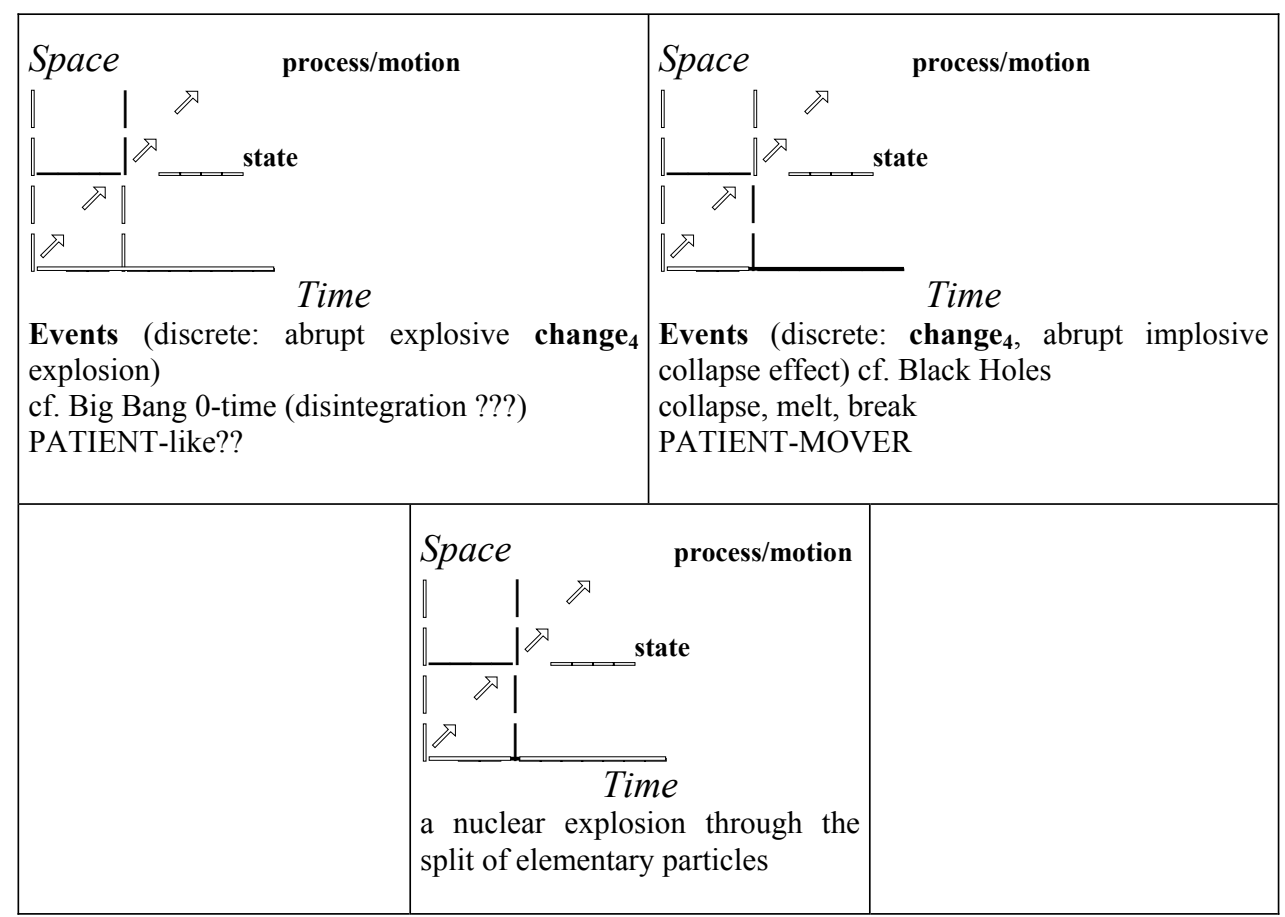

Fig. 9. Speculative spatio-temporal representations for hypothetical explosion-implosion profiles 
More philosophically, creation/becoming alive vs. decay/dying (in terms of the very terminal points of both processes); as can be seen from the representation below, as the conception of eternity requires a zero value for time, as below:

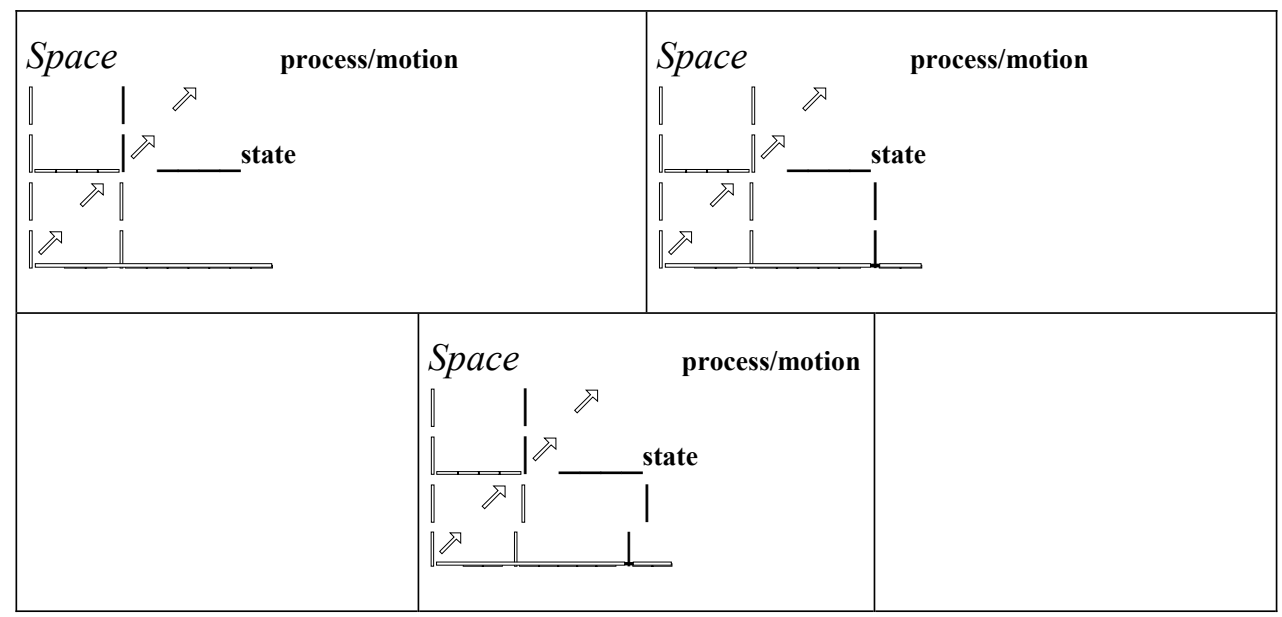

Fig. 10. Hypothetical representations for to create and to die (as a 'near-zero-time' abrupt processes).

(Separate representations for gradual-temporal mode would also be possible.)

\section{An attempt at an integration of lexical and grammatical aspects}

Let us now return to the question of lexical aspect (inceptiveness, telicity, duration, habituality etc.) and try to establish its possible correlation with the grammatical aspect (progressive continuity and perfective anteriority), (cf. topological 'translation' involving the three conventions). Granularity level below has been further 'translated' into more specific representations. Note the three conventions (a) spatio-temporal coordinates, (b) object-like granularity (c) a 'commonsensical' graphic representation: 


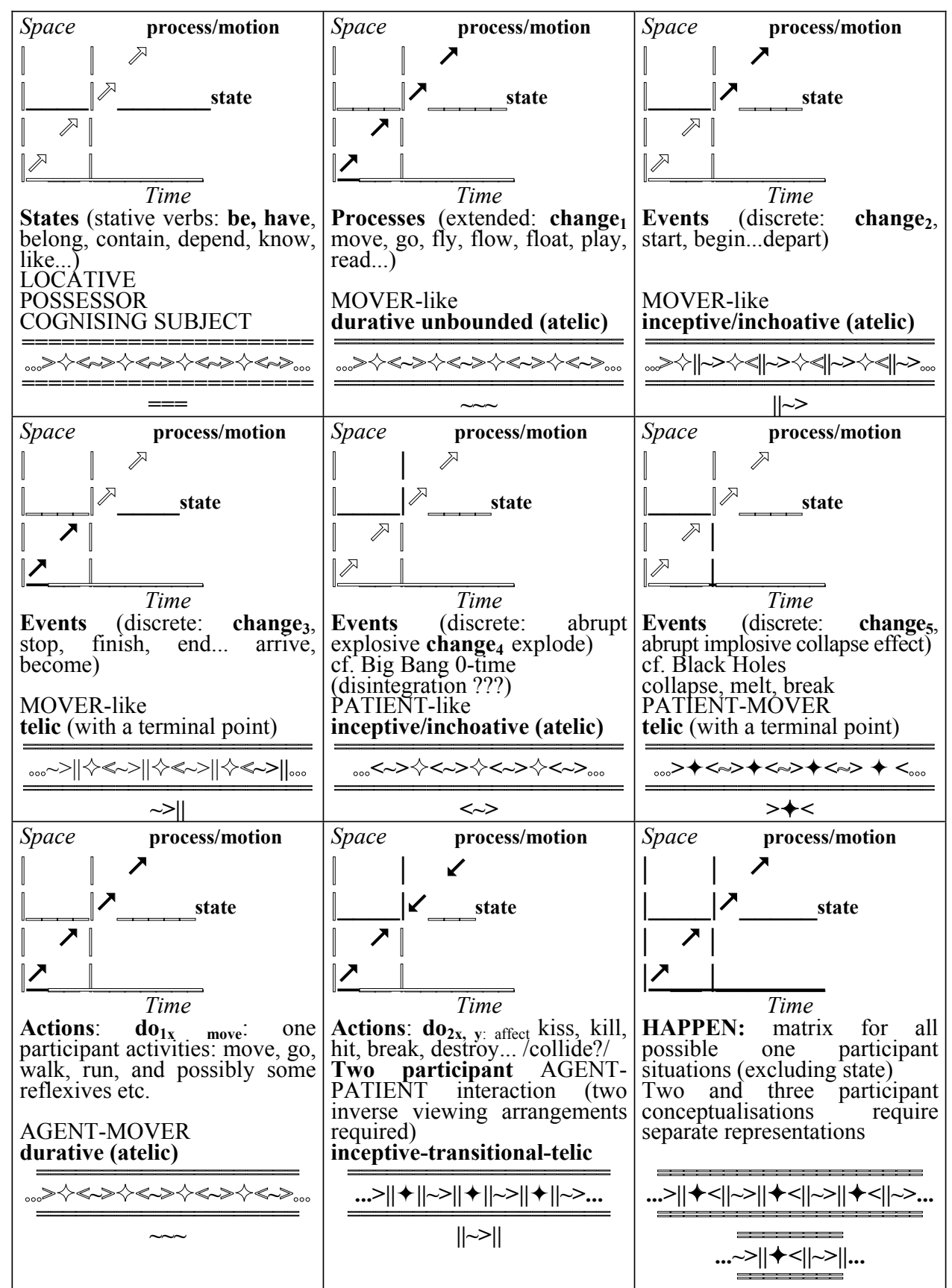

Fig. 11. The three conventions (1) the space-time coordinates for the lexical aspect, (2) the event (entity) - process (substance) - state (container) for the grammatical aspect (3) an attempt to integrate both (1 and 2) 
Thus, the 'topological translation' allows to render the following reformulations, along with granularity, which will later accommodate blending of grammatical and lexical aspects and possible verb constructions and their concatenations:

\begin{tabular}{|c|c|c|c|c|c|c|c|}
\hline STATIVE: & \multicolumn{7}{|c|}{$\begin{array}{l}\text { DYNAMIC: EVENT/PROCESS/ACTION - HAPPEN = CHANGE in one of the } \\
\text { ways below }\end{array}$} \\
\hline $\begin{array}{l}1 . \\
\text { BE } \\
\text { HAVE } \\
\text { OWN } \\
\text { POSSESS } \\
\text { CONTAIN } \\
\text { CONSIST } \\
\text { of } \\
\text { BELONG } \\
\text { to } \\
\text { DEPEND } \\
\text { on } \\
----------- \\
\text { KNOW } \\
\text { BELIEVE } \\
\text { LIKE etc. }\end{array}$ & $\begin{array}{l}2 . \\
\text { START } \\
\text { BEGIN } \\
\text { GO } \\
\text { AWAY } \\
\text { DEPART }\end{array}$ & \begin{tabular}{|l}
3. \\
MOVE \\
GO \\
FLOAT \\
FLY \\
PLAY \\
READ \\
\\
--path--
\end{tabular} & \begin{tabular}{|l}
4. \\
STOP \\
END \\
FINISH \\
FALL \\
COME \\
ARRIVE \\
\\
--- goal >• \\
BECOME \\
\\
Non- \\
agentive \\
COME to \\
EXIST \\
Agentive \\
MAKE \\
CREATE
\end{tabular} & $\begin{array}{l}5 . \\
\text { EXPLODE } \\
\text { BREAK } \\
\text { UP }\end{array}$ & $\begin{array}{l}6 . \\
\text { COLLAPSE } \\
\text { BREAK } \\
\text { DOWN }\end{array}$ & \begin{tabular}{|l|} 
TRANSIT. \\
OF \\
ENERGY \\
Agonist- \\
Antagonist \\
(AG-PAT) \\
OBJECT \\
(AG-MVR- \\
REC) \\
STIMULUS \\
(STIM- \\
EXP) \\
•---------- \\
TRANSFER
\end{tabular} & $\begin{array}{l}8 . \\
\text { All the } \\
\text { other } \\
\text { situations } \\
1-6 \\
\text { also } \\
\text { possible } \\
\text { for } \\
\text { cognising } \\
\text { agents } \\
\text { AG/MVR } \\
\text { AG/EXP }\end{array}$ \\
\hline $\begin{array}{c}\text { be } \\
===== \\
=|=|=\mid= \\
\text { have }\end{array}$ & $\| \sim>$ & $\sim \sim \sim$ & $\sim>\|$ & $<\sim>$ & $\sim><<$ & $\|\sim>\|$ & \\
\hline
\end{tabular}

Fig. 12. Simple aspectual representations of basic verbs along the state-change spectrum, to be considered in terms of intransitive and possible transitive (whenever relevant)

Now, let us consider a few examples for which we shall propose profiles merging both lexical aspect and morpho-grammatical aspect. Grammatical progressive and perfective aspects are, in fact, highly distinct by virtue of the continuity (cf. substance-like and allowing multiplex to mass transformations) vs. anteriority relative to a temporal reference point (tense as such stands for discoursive grounding of time). Verbs BE and HAVE display mutual duality, which can be demonstrated in the following construals:

There is a spot on your shirt.

Your shirt has a spot on it. 
Russian alternation with English:

U menya [jest'] kniga (at me [is] a book)

I have a book

Polish alternation between affirmative and negative forms:

Jestem. vs. Nie ma mnie.

In the representation below we need to accommodate the following parameters:

1. Grammatical progressive aspect employs the $\mathrm{BE}+\mathrm{V}$-ing construction (the present participle can be likened to unbounded substance-like mass $\sim$ multiplex dual).

2. Grammatical perfective aspect employ the HAVE $+\mathrm{V}$-ed/en construction for anterior events and states, thus can be likened respectively to uniplex entities and mass-like substances anterior to a temporally structured boundary (discrete point).

3. Moreover, infinitives and present and past participles have a cognitive status of landmarks of atemporal relations (cf. Langacker 2001).

4. If we add the concatenation of verbs of various brands of lexical aspect then the situation begins to be (=becomes) highly complex and equally interesting due to the combinatorial explosion of image schematic parameters. 


\begin{tabular}{|c|c|}
\hline He is beginning (to conduct) the class & $\begin{array}{c}==============\text { is } \\
\text { begin }\|\sim>\| . \sim>\|\ldots \sim>\| \ldots \ldots \sim>\text {-ing... } \\
\text { to } \sim \sim \sim \sim \sim \sim \sim \sim \sim \sim \sim \sim \sim \sim \sim \text { conduct } \ldots \\
===============\text { is }\end{array}$ \\
\hline He has begun (to conduct) the class & $\begin{array}{l}=|=|=|=|=\text { has } \\
\text { be } \| \ldots \sim>\text { gun } \\
\text { to } \sim \sim \sim \sim \sim \sim \sim \text { conduct... } \\
=|=|=|=|=\text { has }\end{array}$ \\
\hline Now, he is conducting the class & $\begin{aligned} &==============\text { is } \\
& \ldots \mathrm{V} \sim \sim \sim \sim \sim \sim \sim \sim \sim \sim \sim \sim \sim \text {-ing... } \\
&=============\text { is }\end{aligned}$ \\
\hline He is going away & $\begin{array}{c}=============\text { is } \\
\mathrm{V} \| \ldots \sim>\ldots \ldots \sim>\ldots \ldots \sim>\ldots \ldots .>\text {...... }>\text {-ing......(away) } \\
=============\text { is }\end{array}$ \\
\hline He has gone away & $\begin{array}{l}=|=|=|=|=\text { has } \\
\text { go }|| \sim>\text { ne... (away) } \\
=|=|=|=|=\text { has }\end{array}$ \\
\hline He is beginning to fly & $\begin{array}{c}==============\text { is } \\
\text { begin }\|\sim>\| \ldots \sim>\|\ldots \ldots \sim>\| \ldots \ldots \ldots \sim>\text {-ing } \ldots \ldots . . . \\
\text { to } \sim \sim \sim \sim \sim \sim \sim \sim \sim \sim \sim \sim \sim \sim \text { fly } \\
===============\text { is }\end{array}$ \\
\hline He has begun to fly (he has taken off) & $\begin{array}{l}=|=|=|=|=\text { has } \\
\text { be } \| \ldots \sim>\text { gun } \\
\text { to } \sim \sim \sim \sim \sim \text { fly }[\text { the flight }[\sim \sim \sim \sim \sim \sim \mathrm{N} \leftarrow \mathrm{V} \\
=|=|=|=|=\sim \text { has }\end{array}$ \\
\hline He is beginning to move, fly & $\begin{array}{c}==============\text { is } \\
\text { begin }\|\sim>\| \ldots \sim>\|\ldots \ldots \sim>\| \ldots \ldots \sim>\text {.ing } \ldots \\
\text { to } \sim \sim \sim \sim \sim \sim \sim \sim \sim \sim \sim \sim \sim \text { move/fly } \\
===============\text { is }\end{array}$ \\
\hline He has begun to move & $\begin{array}{l}=|=|=|=|=\text { has } \\
\text { be } \| \ldots \sim>\text { gun } \\
\text { to } \sim \sim \sim \sim \sim \text { move } \\
=|=|=|=|=\text { has }\end{array}$ \\
\hline He is moving, flying, playing, reading & $\begin{array}{c}==============\text { is } \\
\text { move/fly.. } \sim \sim \sim \sim \sim \sim \sim \sim \sim \sim \sim \sim \sim \sim \sim \ldots \text {-ing } \\
=============\text { is }\end{array}$ \\
\hline $\begin{array}{l}\text { He has moved, flown, played, read y } \\
\text { (x times) [extra segmentation] }\end{array}$ & $\begin{array}{l}=|=|=|=|=|=|=|=|=\text { has } \\
\mathrm{V}[\sim>][\sim>][\sim>][\sim>]-\mathrm{ed} / \mathrm{en} \\
=|=|=|=|=|=|=|=|=\text { has }\end{array}$ \\
\hline $\mathrm{He}$ is finishing the class & $\begin{array}{c}=============\text { is } \\
\text { finish } \ldots . \sim>\ldots \ldots \ldots .\|\sim>\ldots . .\| \sim>\ldots . .\|\sim>. .\| \text {-ing } \\
============\text { is }\end{array}$ \\
\hline He has finished (to conduct) the class & $\begin{array}{l}=|=|=|=|=\text { has } \\
\ldots \sim>|| \\
=|=|=|=|=\text { has }\end{array}$ \\
\hline
\end{tabular}




\begin{tabular}{|c|c|}
\hline The balloon is falling & 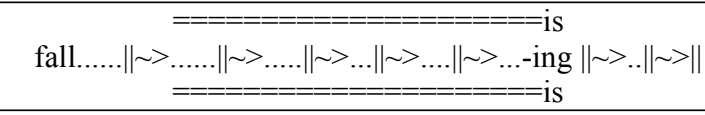 \\
\hline The balloon is beginning to fall & $\begin{array}{c}===================\text { is } \\
\text { begin }\|\sim>\| . . \sim\|\ldots \sim>\| \ldots \ldots \sim>\| \ldots \text { ing } \\
\text { to } \ldots . \sim>\ldots \ldots . . \sim>\ldots \ldots\|\sim>\ldots .\| \sim \| \\
==================\text { is }\end{array}$ \\
\hline The balloon has begun to fall & $\begin{array}{l}=|=|=|=|=\text { has } \\
\text { be } \| \ldots \ldots \sim>\text { gun } \\
\text { to } \sim>\ldots . . \| \text { fall } \\
=|=|=|=|=\text { has }\end{array}$ \\
\hline The stone has fallen & $\begin{array}{l}=|=|=|=|=\text { has } \\
\text { fall }>\||| \text { en } \\
=|=|=|=|=\text { has }\end{array}$ \\
\hline He is coming & $\begin{array}{c}===============\text { is } \\
\text { come }\|\sim>\ldots . .\| \sim \ldots . . \| \sim \ldots . . \sim \sim \ldots \text {-ing }\|\sim>\|>\| \ldots \\
================\text { is }\end{array}$ \\
\hline *He is beginning to come & $?$ \\
\hline$* \mathrm{He}$ is finishing to come & $?$ \\
\hline *He is beginning to arrive & $?$ \\
\hline *He is finishing to arrive & $?$ \\
\hline He has come, arrived, fallen... & $\begin{array}{l}=|=|=|=|=\text { has } \\
V \sim>|| \text {-en } \\
=|=|=|=|=\text { has }\end{array}$ \\
\hline ??? $\mathrm{X}$ is exploding/breaking up & $\begin{aligned} &==================\text { is } \\
& \ldots V<\sim><\sim><\sim><\sim><\sim><\sim><\sim>\text {-ing } \ldots \\
&===================\text { is }\end{aligned}$ \\
\hline X has exploded/broken up & $\begin{array}{l}=|=|=|=|=\text { has } \\
\mathrm{V}\|<\sim>\| \text {-ed } / \text {-en } \\
=|=|=|=|=\text { has }\end{array}$ \\
\hline ??? $\mathrm{X}$ is collapsing/breaking down & $\begin{array}{c}==================\text { is } \\
\ldots V><><><><><><><><><\text {-ing... } \\
==================\text { is }\end{array}$ \\
\hline $\mathrm{X}$ has collapsed/broken down & $\begin{array}{l}=|=|=|=|=|=|=\text { has } \\
V \sim><<\sim \text {-ed } / \text {-en } \\
=|=|=|=|=|=|=\text { has }\end{array}$ \\
\hline $\begin{array}{l}\text { The balloon has been moving, flying } \\
\text { The river has been flowing } \\
\text { He has been reading }\end{array}$ & $\begin{array}{l}=|=|=|=|=|=|=|=|=\mid=\text { has } \\
=============\text { been } \\
\ldots V \sim \sim \sim \sim \sim \sim \sim \sim \sim \text {-ing... } \\
=============\text { been } \\
=|=|=|=|=|=|=|=|=\mid=\text { has }\end{array}$ \\
\hline $\begin{array}{l}\text { She has been coming here every day } \\
\text { since May (segmentation of telic verbs) }\end{array}$ & $\begin{array}{l}=|=|=|=|=|=|=|=|=\mid=\text { has } \\
============\text { been } \\
{[\sim>||][\sim>||][\sim>||][\sim>||][\sim>||]} \\
===========\text { been } \\
=|=|=|=|=|=|=|=|=\mid=\text { has }\end{array}$ \\
\hline $\begin{array}{l}\text { He has not come here even once since } \\
\text { May }\end{array}$ & $\begin{array}{l}=|=|=|=|=\text { has } \\
\varnothing \text { neg V-ed } / \text {-en } \\
=|=|=|=|=\text { has }\end{array}$ \\
\hline
\end{tabular}

Fig. 13. Grammatical and lexical aspectual profiles integrated 
It is assumed that image-schematic transformations (e.g. involving uniplex multiplex $\sim$ mass $\sim$ containment) are bound to display some pattern of regularity for both atemporal and temporally profiled 'ontologies'. Very much like there is a way to bind the grammatical and lexical aspect with infinitival complements, there should also be a certain bridge between grammatical and lexical aspect and gerundive complements as well as infinitives of purpose.

Consider the valency of the following component and composite structures:

\begin{tabular}{|c|c|c|}
\hline \multirow{2}{*}{$\begin{array}{l}\text { kept: } \\
\text { run: } \\
\text { He kept running. (carried on a process) }\end{array}$} & $\begin{array}{l}============== \\
==============\end{array}$ & {$[\sim \sim \sim \sim \sim \sim] \mathrm{N} \leftarrow \mathrm{V}$-ing } \\
\hline & \multicolumn{2}{|c|}{$\begin{array}{c}======================= \\
{[\sim \sim \sim \sim \sim \sim \sim \sim \sim \sim \sim \sim \sim] N \leftarrow \mathrm{V} \text {-ing }}\end{array}$} \\
\hline \multirow{2}{*}{$\begin{array}{l}\text { stop: } \\
\text { smoke: } \\
\text { He stopped smoking. (terminated a process) }\end{array}$} & $\sim>\ldots . .\|\sim . ..\| \sim\|\|$ & {$[\sim \sim \sim \sim \sim \sim] N \in V$-ing } \\
\hline & \multicolumn{2}{|c|}{$\begin{array}{l}\sim>\ldots . . .\|\sim>. .\| \sim>\| \\
{[\sim \sim \sim \sim \sim \sim n}\end{array}$} \\
\hline \multirow{2}{*}{$\begin{array}{l}\text { stop: } \\
\text { smoke: } \\
\text { He stopped to smoke. } \\
\text { (stopped on purpose in order to initiate } \\
\text { a process) }\end{array}$} & $\sim>\ldots . . .\|\sim>..\| \sim>\|$ & (in order) to $\sim \sim \sim \sim \sim \mathrm{V}$ \\
\hline & \multicolumn{2}{|c|}{$\sim>. . . .\|\sim>..\| \sim>\|$ (in order) to $\sim \sim \sim \sim \mathrm{V}$} \\
\hline \multirow{2}{*}{$\begin{array}{l}\text { begin: } \\
\text { raining: } \\
\text { It began raining. (a process began) }\end{array}$} & $\|\sim>\| . . \sim>\| \ldots .>$ & {$[\sim \sim \sim \sim \sim \sim \sim \sim \sim \sim] N \in \mathrm{V}$} \\
\hline & \multicolumn{2}{|c|}{ 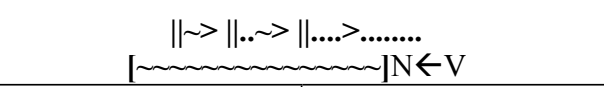 } \\
\hline \multirow{2}{*}{$\begin{array}{l}\text { begin: } \\
\text { rain: } \\
\text { began to rain. (a process began ) }\end{array}$} & \multirow{2}{*}{\multicolumn{2}{|c|}{ 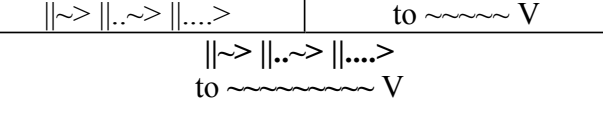 }} \\
\hline & & \\
\hline \multirow{2}{*}{$\begin{array}{l}\text { tried: } \\
\text { to open: } \\
\text { tried to open the door. } \\
\text { (made an effort to accomplish a goal) } \\
\end{array}$} & $\sim[\sim] \sim \sim \sim \sim$ & to $\sim>. . . .\|\sim>..\| \sim>\| V$ \\
\hline & \multicolumn{2}{|c|}{$\begin{array}{l}\sim[\sim] \sim \sim \sim \sim \sim \sim \sim \sim \sim \\
\text { to } \sim>\ldots . . .\|\sim>. .\| \sim>\| V\end{array}$} \\
\hline \multirow{2}{*}{$\begin{array}{l}\text { tried: } \\
\text { opening: } \\
\text { He tried opening the door. } \\
\text { (experimented, tested one of the possible } \\
\text { solutions) }\end{array}$} & 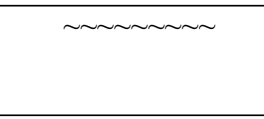 & $\begin{array}{c}{[\sim>\ldots . .\|\sim . . .\| \sim>\|]} \\
\quad \mathrm{N} \leftarrow \mathrm{V} \text {-ing }\end{array}$ \\
\hline & \multicolumn{2}{|c|}{$[\sim>. . .\|\sim>..\| \sim>\|\| \mathrm{N} \leftarrow \mathrm{V}$-ing } \\
\hline
\end{tabular}

Fig. 14. An attempt at a representation of grammatical and lexical aspects along with various infinitival and deverbal nominal (gerundive) constructions. 


\section{Conclusion}

The above attempts to render the temporal profiling through topological representations shed light on conceptualisation as a highly integrated phenomenon along such spectra as space and time whose phenomenological entities are encoded variously as nouns and verbs, with various degrees of boundedness and discreteness. The issue of granularity seems to be crucial for both, conceptualisation of nouns and verbs, and renders the mutual conceptual convertibility of both categories. Very much like in the case of the noun phrase which can be modified by various prepositional phrases, verb phrases and, in particular, verb complementation undergo similar conceptual processes during the merging of grammatical and lexical aspects, and further concatenations of verbs into further compositional profiles.

Further research must concentrate on more unification and refinement in terms of notation, and also must account for multi-argument verbs with greater detail. Conceptual generalities interfacing other modes of encoding in English and other languages await additional identification and due exploration.

\section{References}

C roft, W. A. 1991. Syntactic Categories and Grammatical Relations: The Cognitive organization of Information. Chicago: The University of Chicago Press.

C r o ft, W. A. 2003. Radical Construction Grammar. Oxford: Oxford University Press.

Crysta 1, D. 1991. A Dictionary of Linguistics and Phonetics. Third Edition. Oxford UK Cambridge MA. Basil Blackwell.

Gärdenfors, P. 2001. Conceptual Spaces: The Geometry of Thought. Cambridge, Mass./London, England: MIT Press.

J a c k e n d o ff, R. 1991. Semantic Structures. Cambridge MA - London, England: MIT Press.

J o h n s o n, M. 1987. Body in the Mind: The Bodily Basis of Meaning, Imagination and Reason. Chicago/London: University of Chicago Press.

L a k of f, G. 1997. Women, Fire and Dangerous Things: What Categories Reveal about the Mind. Chicago/London: University of Chicago Press.

L a k off, G. and E. Sw e e ts e r. 1998. Foreword to the Cambridge edition of G. Fauconnier's Mental Spaces, Cambridge: Cambridge University Press.

L a n g c k e r, R. W. 1987. Foundations of Cognitive Grammar, Vol. I., Theoretical Prerequisites. Stanford: Stanford University Press.

L a ng a ker, R. W. 1990. Concept, Image and Symbol: The Cognitive Basis of Meaning. Berlin/New York: Mouton de Gruyter.

L a n g c ke r, R. W. 2000. Grammar and Conceptualization. Berlin/New York: Mouton de Gruyter.

M a t t h e w s, P. H. 1997. Oxford Concise Dictionary of Linguistics. Oxford-New York: Oxford University Press.

S krzy p z z a, W. 1991, 'A synthetic approach to the teaching of grammar: cognitive modeling'. An unpublished paper read at The $25^{\text {th }}$ International Conference of IATEFL - International Association of Teachers of English as a Foreign Language - Exeter, England. 
S k z y p c zak, W. 1989. Supplementary Materials for the EFL Classroom. Toruń: Nicholaus Copernicus University Press.

Skrzy p z z k, W. 2001. "The English Verb System Systematically Represented: A Heuristic Model for Practical and Theoretical Applications". Acta Universitatis Lodziensis, Folia Linguistica Anglica 3.

Skrzypczak, W. 2005. 'Cognitive dimensions of grammar and meaning. A survey of cognitive linguistic metalanguage'. Acta Universitatis Nicholai Copernici. English Studies XIV - Humanities and Social Sciences. Vol. 375.

Skrzypczak, W. 2006, Analog-based Modelling of Meaning Representations in English. Toruń: Nicolaus Copernicus University Press.

Sta lmaszczyk, P. 1999. Structural Predication in Generative Grammar. Łódź: Łódź University Press.

T a $1 \mathrm{~m}$ y, L. 2000. Towards a Cognitive Semantics. Vol I: Concept Structuring Systems. Cambridge, MA - London, England: Bradford Book, MIT Press.

Van Valin, R. D. and R. LaPolla. 1997. Syntax: Structure, Meaning and Function. Cambridge: Cambridge University Press. 